\title{
Electrochemical Polymerization of 1,10-Decanedithiol in $\mathrm{CH}_{3} \mathrm{CN}$
}

\author{
Kiyoshi ENDO ${ }^{\dagger}$ and Hang-Beom Bu \\ Department of Applied Chemistry, Faculty of Engineering, Osaka City \\ University, Sugimoto, Sumiyoshi-ku, Osaka 558-8585, Japan
}

(Received August 17, 2000; Accepted October 26, 2000)

\begin{abstract}
Synthesis of disulfide polymer by electrochemical polymerization of 1,10-decanedithiol (DEDT) in acetonitrile $\left(\mathrm{CH}_{3} \mathrm{CN}\right)$ was investigated. Pt electrode and $\mathrm{Bu}_{4} \mathrm{NClO}_{4}$ as supporting electrolyte were found to be suitable for the electrochemical polymerization of DEDT. The polymerization of DEDT proceeded to give polymer in good yields, and the obtained polymers were found to be a linear disulfide polymer. The polymer yield was proportion to current quantum, but $M_{\mathrm{n}}$ of the polymer did not depend on both monomer concentration and current quantum. The polymer yield increased by the addition of dibenzyldisulfide (DBDS).

KEY WORDS Electrochemical Polymerization / 1,10-Decanedithiol / Polymer Containing Disulfide Bond / Dibenzyldisulfide / $\alpha, \omega$-Alkanedithiol /
\end{abstract}

The polymers containing disulfide bonds in the main chain have received much attention for a long time from its unique chemical properties. ${ }^{1-3}$ The disulfide bond can exist at various types of stable compounds, ${ }^{4-8}$ while peroxide compounds are not stable. Among many disulfide compounds, cyclic 1,2-disulfides are synthesized by the oxidation of $\alpha, \omega$-dithiol compounds with a suitable oxidant such as hydrogen peroxide and iron trichloride, ${ }^{1,4,9}$ and these are very useful monomers for preparing polymer containing disulfides bonds. However, it is difficult to induce ring-opening polymerization of cyclic disulfides by thermal under a dilute monomer condition. ${ }^{10}$ On the other hand, electrochemical polymerization seems to be an useful method for preparing polymers containing disulfide bonds from direct polymerization of $\alpha, \omega$-dithiol compounds under a dilute monomer condition.

In an electrochemical field, disulfide compounds have been investigated as candidates for high energy cathodes in lithium batteries, ${ }^{10-15}$ which can be regarded as a reversible polymerization-depolymerization system. ${ }^{5,6,16,17}$ In redox polymerization of dithiol compounds, various polymers were synthesized by number of routes including aqueous oxidation by iodine or other oxidants. However, electrochemical polymerization of $\alpha$, $\omega$-alkanedithiol compounds except for ethanedithiol were not examined in detail. It is, thus, interesting to investigate the synthesis of polymer containing disulfide bond from $\alpha, \omega$-dithiol compounds by electrochemical polymerization.

We selected 1,10-decanedithiol (DEDT) as a monomer from preliminary polymerization of $\alpha, \omega$-alkyldithiol, and electrochemical polymerization of DEDT was investigated to find suitable polymerization conditions. The results of electrochemical polymerization of DEDT will be described in this paper.

\section{EXPERIMENTAL}

\section{Materials \\ DEDT (Aldrich Chem.) was purified by distillation un-}

${ }^{\dagger}$ To whom correspondence should be addressed. der reduce pressure before use. Commercially available 1,3-propanedithiol (PRDT), 1,4-butanedithiol (BUDT), 1,5-pentanedithiol (PEDT) and 1,6-hexanedithiol (HEDT) were used without further purification. Dibenzyldisulfide (DBDS) and other reagents were purified by conventional methods.

\section{Electrochemical Polymerization}

Electrochemical polymerization was carried out in a single compartment cell equipped with a stirrer, electrode and stopcock. Required amounts of reagents were charged in the cell by syringes through a stopcock under nitrogen atmosphere. Carbon (diameter $0.8 \mathrm{~mm}$, length $30 \mathrm{~mm}$ ), magnesium, copper (diameter $10 \mathrm{~mm}$, length 30 $\mathrm{mm}$ ), and platinum (length $20 \mathrm{~mm}$ wide $20 \mathrm{~mm} \times 2$ ) were used as electrodes. Required current quantum was passed through the cell at $7 \mathrm{CV}$ (constant potential). The reaction temperature was kept at $0^{\circ} \mathrm{C}$ and the system was stirred during the reaction. The contents of the cell were poured into a large amount of methanol to isolate polymeric products and dried in vacuum. The polymer yield was determined by gravimetry.

\section{Characterization}

The number-average molecular weight $\left(M_{\mathrm{n}}\right)$ and the weight-average molecular weight $\left(M_{\mathrm{w}}\right)$ of the polymer were determined by GPC using Tosoh GPC-8000 series in tetrahydrofuran (THF) at $38^{\circ} \mathrm{C}$ calibrated as standard polystyrenes. The structure of the polymer was determined by ${ }^{1} \mathrm{H}$ and ${ }^{13} \mathrm{C} \mathrm{NMR}$ spectra measured in $\mathrm{CDCl}_{3}$ at $20^{\circ} \mathrm{C}$ with tetramethylsilane (TMS) as an internal standard using JEOL A-400 spectrometer. The melting point $\left(T_{\mathrm{m}}\right)$ of polymers was measured by differential scanning calorimetry (DSC) using SEIKO, S II EXSTAR 6000 thermal analyzer at a heating rate of $10^{\circ} \mathrm{C} \mathrm{min}^{-1}$ under nitrogen atmosphere.

\section{RESULS AND DISCUSSION}

\section{Electrochemical Polymerization of Various Dithiol Com- pounds}

Table I shows the results of the electrochemical polymerization of $\alpha, \omega$-alkanedithiols. The polymerization 
of all monomers proceeded expect for BUDT which gave mainly 1,2-dithiane. Polymerization was found to depend on the alkyl chain length of the monomer. DEDT gave polymer in a higher yield than others, although the molecular weight of poly(DEDT) was lower than that of PEDT and HEDT. So the electrochemical polymerization of DEDT was investigated in detail.

\section{Effect of Electrode}

In electrochemical polymerizations, it is well known that electrode plays an important role to determine polymerization behavior and polymer character such as molecular weight and its distribution. ${ }^{18}$ So the effect of electrode on electrochemical polymerization of DEDT was examined, and the results are listed in Table II. The electrochemical polymerization of DEDT was found to be influenced by the kind of electrode. Among the electrodes examined, we concluded that $\mathrm{Pt}$ was the most preferential electrode for the polymerization of DEDT by the following reasons.

No polymeric products were obtained, when carbon or magnesium electrode was employed. In the polymerization of $\alpha, \omega$-alkanedithiols, the absorption of thiol group on the electrode surface is seemed to play an important, and many attention have been focused on the studies of self-assembled monolayer on gold ${ }^{19}$ and platinum ${ }^{20}$ electrodes using thiol compounds. The polymerization of DEDT with carbon electrode gave no polymeric product, this may be attributed to no affinity or chemisorption between thiol group and carbon electrode. On the other hand, the oxidation potential of magnesium is very low $\left(E_{0}=-2.363 \mathrm{~V}\right)$. Thus, in the polymerization of DEDT with magnesium electrode, the oxidation of magnesium at anode is likely to progress preferentially rather than that of thiol groups to form of disulfide bonds. Polymerization products obtained with $\mathrm{Cu}$ electrode did not dissolve in any common solvents such as toluene and THF. Moreover, the $T_{\mathrm{m}}$ of the product was not observed in contrast to that the polymer obtained with $\mathrm{Pt}$ electrode showed the $T_{\mathrm{m}}$ at $46.4^{\circ} \mathrm{C}$. Sulfur compounds are known to combine easily with copper to form S-Cu bond. ${ }^{20,21}$ Thus, the electrochemical polymerization of DEDT with $\mathrm{Cu}$ electrode is likely to yield in organic copper compounds containing $\mathrm{S}-\mathrm{Cu}$ bond, although the fine structure of the products was not determined.

The structure of polymer obtained with $\mathrm{Pt}$ electrode was determined by ${ }^{13} \mathrm{C}$ NMR spectroscopy. The spectrum of the polymer is shown in Figure 1, in which the spectrum of DEDT is also indicated to comparison. The poly(DEDT) revealed signals at $28.2 \mathrm{ppm}, 28.9 \mathrm{ppm}, 29.2$ $\mathrm{ppm}$, and $38.8 \mathrm{ppm}$ based on methylene carbon for the structures bearing S-S bond as shown in Figure 1. Small signals of methylene carbon adjacent to the thiol group were also observed at $24.2 \mathrm{ppm}, 27.9 \mathrm{ppm}, 28.6 \mathrm{ppm}$, $29.0 \mathrm{ppm}$, and $33.6 \mathrm{ppm}$. $^{4}$ This indicates that electrochemical polymerization of DEDT with Pt electrode yielded in the linear disulfide polymer with thiol group at the chain end.

\section{Effect of Supporting Electrolyte}

Many supporting electrolytes were used in electrochemical reactions of organic compounds. ${ }^{22,23}$ To find a suitable supporting electrolyte for the polymerization of
Table I. Electrochemical polymerization of $\alpha, \omega$-alkanedithiol with $\mathrm{Pt}$ electrode in $\mathrm{CH}_{3} \mathrm{CN}$ at $0^{\circ} \mathrm{C}^{\mathrm{a}}$

\begin{tabular}{ccccc}
\hline $\begin{array}{l}\alpha, \omega \text {-Alkane- } \\
\text { dithiol }\end{array}$ & $\begin{array}{c}\text { Number of } \\
\text { carbon chain }\end{array}$ & $\begin{array}{c}\text { Polymer } \\
\text { yield/\% }\end{array}$ & $\bar{M}_{\mathrm{n}} \times 10^{-3}$ & $\bar{M}_{\mathrm{w}} / \bar{M}_{\mathrm{n}}$ \\
\hline PRDT & 3 & 1.0 & - & - \\
BUDT & 4 & 0.0 & - & - \\
PEDT & 5 & 4.6 & 16.6 & 2.2 \\
HEDT & 6 & 7.6 & 20.5 & 2.6 \\
DEDT & 10 & 10.7 & 1.6 & 2.8 \\
\hline
\end{tabular}

${ }^{\mathrm{a}}[$ Monomer $]=0.12 \mathrm{~mol} \mathrm{~L}^{-1}, \quad\left[\mathrm{Bu}_{4} \mathrm{NCIO}_{4}\right]=0.15 \mathrm{~mol} \mathrm{~L}^{-1}, \quad$ Constant potential $=7 \mathrm{CV}$, Current quantum $=0.5 \mathrm{Faraday} \mathrm{mol}^{-1}$.

Table II. Effects electrode on the electrochemical polymerization of DEDT in $\mathrm{CH}_{3} \mathrm{CN}$ at $0^{\circ} \mathrm{C}^{\mathrm{a}}$

\begin{tabular}{ccccc}
\hline Electrode & Polymer yield $/ \%$ & $\bar{M}_{\mathrm{n}} \times 10^{-3}$ & $\bar{M}_{\mathrm{w}} / \bar{M}_{\mathrm{n}}$ & $T_{\mathrm{m}}{ }^{\circ} \mathrm{C}$ \\
\hline $\mathrm{C}$ & 0 & - & - & - \\
$\mathrm{Mg}$ & 0 & - & - & - \\
$\mathrm{Cu}$ & $>100^{\mathrm{b}}$ & n.d. $^{\mathrm{c}}$ & n.d. & ${ }^{\mathrm{c}}$ \\
$\mathrm{Pt}$ & 10.7 & 1.6 & 2.8 & 46.4 \\
\hline
\end{tabular}

${ }^{\mathrm{a}}[\mathrm{DEDT}]=0.12 \mathrm{~mol} \mathrm{~L}^{-1}, \quad\left[\mathrm{Bu}_{4} \mathrm{NCIO}_{4}\right]=0.15 \mathrm{~mol} \mathrm{~L}^{-1}$, Constant potential $=7 \mathrm{CV}$, Current quantum $=0.5$ Faraday $\mathrm{mol}^{-1} \cdot{ }^{\mathrm{b}} \mathrm{Cu}$ was included in the polymer. ${ }^{\mathrm{c}}$ Not determined.
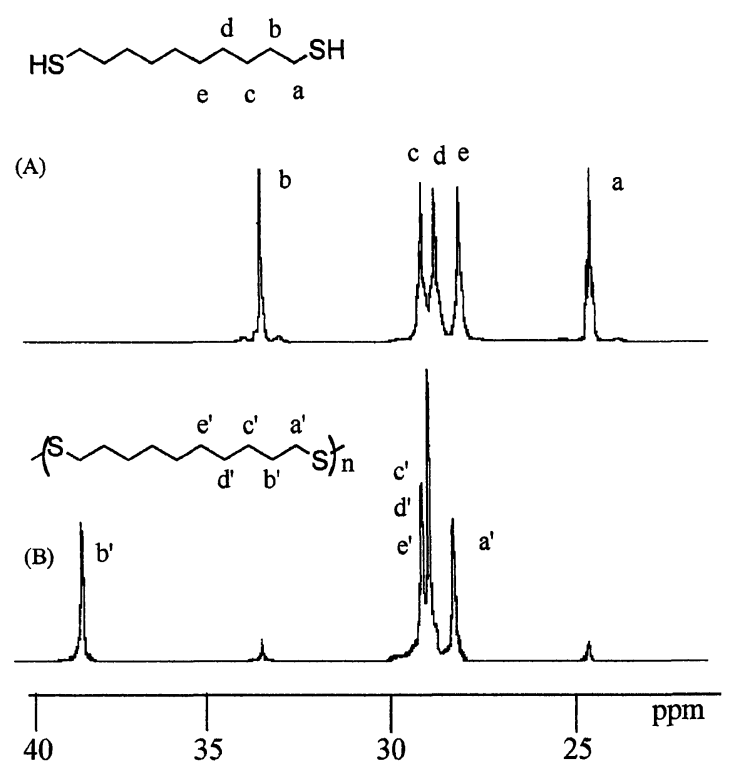

Figure 1. ${ }^{13} \mathrm{C}$ NMR spectra of DEDT (A) and Poly(DEDT) (B).

DEDT with Pt electrode, the polymerization of DEDT with various supporting electrolyte was examined. The results are listed in Table III. Among the supporting electrolyte examined, $\mathrm{LiClO}_{4}$ gave higher molecular weight polymer than others. However, as the reaction progress, reduced lithium compounds was precipitated on the surface of the electrode. This suggests that side reactions between DEDT and Li take place during the polymerization. When tetrabutylammonium tetrafluoroborate $\left(\mathrm{Bu}_{4} \mathrm{NBF}_{4}\right)$ was employed, the current depressed remarkably with reaction time, leading to low polymer yield. Such unfavorable reactions did not take place, when tetrabutylammonium perchlorate $\left(\mathrm{Bu}_{4} \mathrm{NClO}_{4}\right)$ was used. Thus, it is clear that the $\mathrm{Bu}_{4} \mathrm{NClO}_{4}$ is a suitable supporting electrolyte for the polymerization of DEDT 
Table III. Effects of supporting electrolyte on the electrochemical polymerization of DEDT with $\mathrm{Pt}$ electrode in $\mathrm{CH}_{3} \mathrm{CN}$ at $0^{\circ} \mathrm{C}^{\mathrm{a}}$

\begin{tabular}{lccc}
\hline $\begin{array}{l}\text { Supporting } \\
\text { electrolyte }\end{array}$ & Polymer yield/\% & $\bar{M}_{\mathrm{n}} \times 10^{-3}$ & $\bar{M}_{\mathrm{w}} \bar{M}_{\mathrm{n}}$ \\
\hline $\mathrm{LiClO}_{4}$ & 13.3 & 3.2 & 3.0 \\
$\mathrm{Bu}_{4} \mathrm{NBF}_{4}$ & 6.8 & 1.5 & 2.5 \\
$\mathrm{Bu}_{4} \mathrm{NClO}_{4}$ & 10.7 & 1.6 & 2.8 \\
\hline${ }^{\mathrm{a}}[\mathrm{DEDT}]=0.12 \mathrm{~mol} \mathrm{~L}$ & \multicolumn{1}{c}{, [Supporting electrolyte] $=0.15 \mathrm{~mol} \mathrm{~L}^{-1}}$, \\
Constant potential $=7 \mathrm{CV}$, Current quantum $=0.5$ Faraday $\mathrm{mol}^{-1}$.
\end{tabular}

with Pt electrode.

\section{Influence of Current Quantum and DEDT Concentration}

Figure 2 shows the effects of current quantum on the polymer yield and the $M_{\mathrm{n}}$ of polymer for the electrochemical polymerization of DEDT with Pt electrode at constant potential $(7 \mathrm{CV})$, in which the results of the polymerization of DEDT in $\mathrm{CH}_{2} \mathrm{Cl}_{2}$ are also listed to comparison. The polymer yields increased as a function of current quantum in both solvents. Since the electrochemical polymerization of DEDT is considered to proceed through a stepwise intermolecular $\mathrm{S}-\mathrm{S}$ bond formation, ${ }^{24}$ the $M_{\mathrm{n}}$ of polymer is expected to increase with current quantum. However, the $M_{\mathrm{n}}$ of polymer obtained in $\mathrm{CH}_{3} \mathrm{CN}$ did not increase with current quantum. In electrochemical polymerization of DEDT in $\mathrm{CH}_{3} \mathrm{CN}$, the reaction takes place on the surface of electrode. The precipitated polymer, thus, seemed to be difficult to participate again into the polymerization. Since poly(DEDT) is insoluble in $\mathrm{CH}_{3} \mathrm{CN}$ used as polymerization solvent, we presumed that the $M_{\mathrm{n}}$ of polymer did not increase with the current quantum.

If this assumption is correct, the $M_{\mathrm{n}}$ of the polymers will increase with the current quantum in $\mathrm{CH}_{2} \mathrm{Cl}_{2}$. Because the poly(DEDT) is soluble in $\mathrm{CH}_{2} \mathrm{Cl}_{2}$. As shown in Figure 2, the molecular weight of polymers obtained in $\mathrm{CH}_{2} \mathrm{Cl}_{2}$ increased slightly with current quantum. Thus, it is clear that a solubility of the polymers play a role to determine the molecular weight of the polymer.

Figure 3 shows the effects of monomer concentration on the electrochemical polymerization of DEDT with $\mathrm{Pt}$ electrode at constant potential (7 CV). The polymer yield increased with an increase of monomer concentration. On the other hand, the $M_{\mathrm{n}}$ of polymers did not depend on the monomer concentration. The precipitating polymer seems to be caused such behavior.

\section{Addition of $D B D S$}

The effects of DBDS as monothiol on electrolytic polymerization of DEDT were examined. The results are shown in Table IV. The polymer yields increased by the addition of DBDS for the electrochemical polymerization of DEDT. Although the reason is not clear now, it may be related to the active species derived from DBDS may facilitate the conversion of $\mathrm{S}-\mathrm{H}$ bond into $\mathrm{S}-\mathrm{S}$ bond.

The ${ }^{1} \mathrm{H}$ NMR spectrum of the polymer obtained in the presence of DBDS is illustrated in Figure 4. The signals appeared at $3.9 \mathrm{ppm}$ and $7.3-7.5 \mathrm{ppm}$ based on benzyl methylene proton and benzene proton, which were derived from the DBDS. This indicates that benzyl sulfide is introduced in a polymer chain end by the addition of monothiol in the electrochemical polymerization of

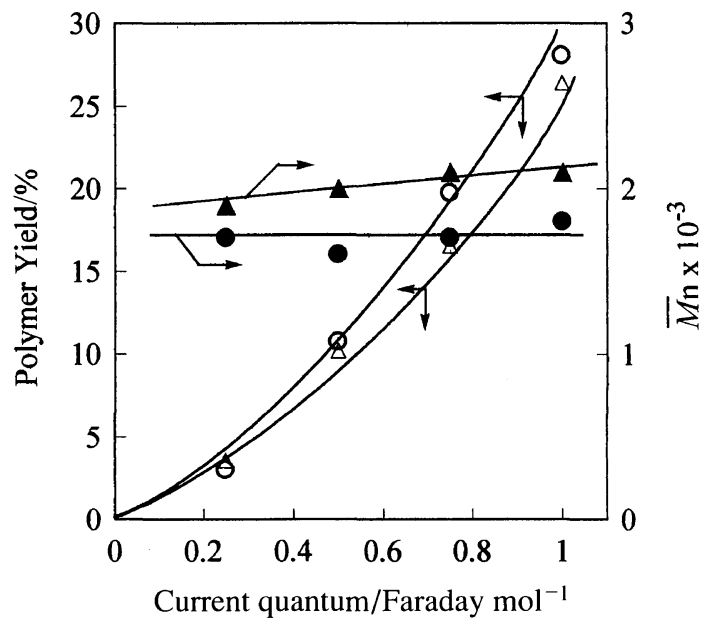

Figure 2. Comparison of the polymerization behavior of DEDT with $\mathrm{Pt}$ electrode at $0^{\circ} \mathrm{C}$ in $\mathrm{CH}_{3} \mathrm{CN}(\mathrm{O}, \mathbf{O})$ and in $\mathrm{CH}_{2} \mathrm{Cl}_{2}(\triangle, \Delta)$ : $[D E D T]=0.12 \mathrm{~mol} \mathrm{~L}^{-1},\left[\mathrm{Bu}_{4} \mathrm{NClO}_{4}\right]=0.15 \mathrm{~mol} \mathrm{~L}^{-1}$, constant potential $=7 \mathrm{CV}$

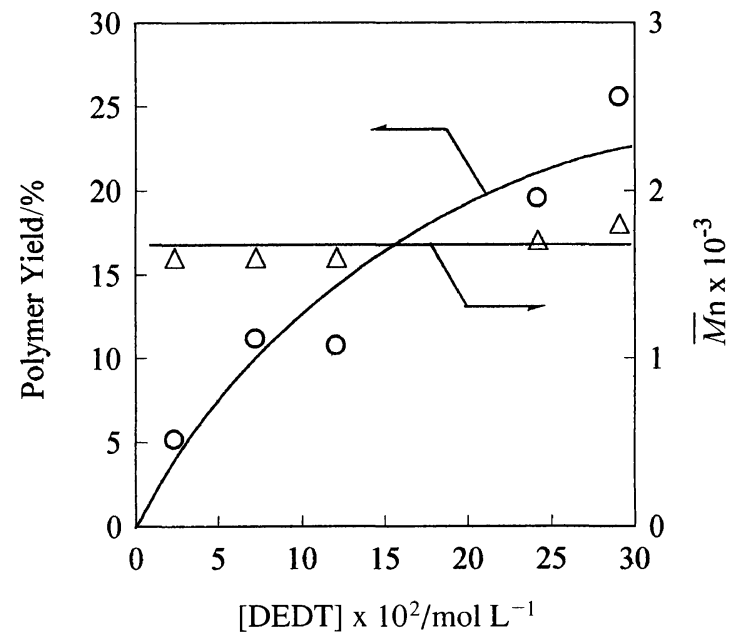

Figure 3. Effects of monomer concentration on the polymerization of DEDT in $\mathrm{CH}_{3} \mathrm{CN}$ with $\mathrm{Pt}$ electrode at $0^{\circ} \mathrm{C}$ : [DEDT] $=0.12$ mol L ${ }^{-1},\left[\mathrm{Bu}_{4} \mathrm{NClO}_{4}\right]=0.15 \mathrm{~mol} \mathrm{~L}^{-1}$, Constant potential $=7 \mathrm{CV}$, Current quantum $=0.7$ Faraday $\mathrm{mol}^{-1}$.

Table IV. Effects of DBDS on the electrochemical polymerization of DEDT with $\mathrm{Pt}$ electrode in $\mathrm{CH}_{3} \mathrm{CN}$ at $0^{\circ} \mathrm{C}^{\mathrm{a}}$

\begin{tabular}{cccc}
\hline \multirow{2}{*}{ Additive } & Polymer yield $/ \%$ & $\bar{M}_{\mathrm{n}} \times 10^{-3}$ & $\bar{M}_{\mathrm{w}} / \bar{M}_{\mathrm{n}}$ \\
\hline - & 10.7 & 1.6 & 2.8 \\
DBDS & 18.5 & 1.4 & 2.7 \\
\hline
\end{tabular}

${ }^{\mathrm{a}}[\mathrm{DEDT}]=0.12 \mathrm{~mol} \mathrm{~L}^{-1}, \quad\left[\mathrm{BU}_{4} \mathrm{NClO}_{4}\right]=0.15 \mathrm{~mol} \mathrm{~L}^{-1}$, Constant potential $=7 \mathrm{CV}$. Current quantum $=0.5$ Faraday $\mathrm{mol}^{-1}$, DBDS/ $\mathrm{DEDT}=0.05$ mole ratio

DEDT.

\section{CONCLUSIONS}

The polymer containing of $\mathrm{S}-\mathrm{S}$ bond in main chain could be synthesized by the electrochemical polymerization of DEDT with Pt electrode in $\mathrm{CH}_{3} \mathrm{CN}$. Pt was a suitable as electrode, and $\mathrm{Bu}_{4} \mathrm{NClO}_{4}$ was a preferable sup- 

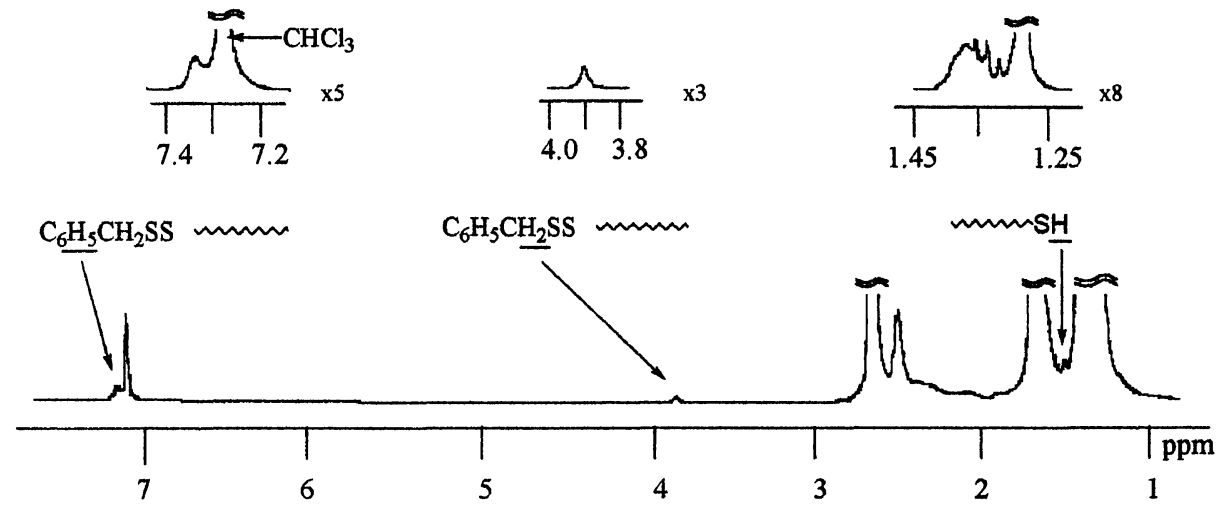

Figure 4. ${ }^{1} \mathrm{H}$ NMR spectrum of poly(DEDT) obtained from the polymerization of DEDT in the presence of DBDS.

porting electrolyte for the polymerization of DEDT. The polymer yields increased with the current quantum supplied and DEDT concentration, but $M_{\mathrm{n}}$ of the polymer was not influenced by the current quantum and DEDT concentration.

Acknowledgment. The authors thank Professor Tsutomu Ohzuku and Associate Professor Keijiro Sawai at Department of Applied Chemistry, Osaka City University, for their helpful assistant of measuring cyclic voltammetry and valuable suggestions.

\section{REFERENCES}

1. R. C. Thomas and L. J. Acid, J. Am. Chem. Soc., 78, 6148 (1956).

2. K. Kshore and K. Ganesh, Adv. Poly. Sci., 121, 81 (1995).

3. S. Kanbara, Ed., "Goseigomu Hand Book", Asakura Shoten, Co., Ltd., Tokyo, 1969, p 245.

4. J. Houk and G. M. Whitesides, J. Am. Chem. Soc., 109, 6825 (1990).

5. R. Singh and G. M. Whitesides, J. Am. Chem. Soc., 112, 6304 (1990).

6. J. A. Burns and G. M. Whtesides, J. Am. Chem. Soc., 112, 626 (1990).

7. K. Morita and S. Kobayashi, Tetrahedron Lett., 1966, 573

8. K. Komiya, S.Kobashi, K. Morita, and Y. Tomiie, Chem. Pharm. Bull ., 15, 756 (1967).

9. E. E. Reid, "Organic Chemistry of Bivalent Sulur", Chemical
Publishing Co., New York, N.Y., 1960, 3, p 362.

10. J. Houk and G. M. Whitesides, Tetrahedron, 45, 91 (1989).

11. S. J. Visco, M. Liu, and L. C. De Joghe, J. Electrochem. Soc., 137, 1191 (1990).

12. M. Liu, S. J. Visco, and L. C. De Joghe, J. Electrochem. Soc., 138, 1891 (1991)

13. M. M. Doeff, M. M. Lerner, S. J. Visco, and L. C. De Joghe, J. Electrochem. Soc., 139, 2077 (1992)

14. M. Ue, S. J. Visco, and L. C. De Joghe, Denki Kagaku, 61, 1409 (1993).

15. Y. Ma, M. M. Doeff, S. J. Visco, and L. C. De Joghe, J. Electrochem. Soc., 140, 2726 (1993).

16. S. J. Visco, C. C. Mailhe, L. C. De Jonghe, and M. B. Armand, J. Electrochem. Soc., 136, 661 (1989).

17. S. J. Visco and L. C. De Jonghe, Mater. Res. Soc. Symp. Proc., 135, 553 (1989).

18. G. Arai, T. Sugaya, M. Sakamoto, and I. Yasumori, Bull. Chem. Soc. Jpn., 65, 594 (1992).

19. K. B. Jirage, J. C. Hulteen, and C. R. Martin, Anal. Chem., 71, 4913 (1999).

20. R. Michalitsch, C. Nogues, A. Najari, A. Eikassmi, A. Yassar, P. Lang, and F. Garnier, Synth. Met., 101, 5 (2000).

21. I. Solomon, P. J. Clendening, H. B. Gray, and F. J. Grunthaner, J. Am. Chem. Soc., 97, 3878 (1975).

22. G. S. Patterson and R. H. Holm, Biochemistry, 4, 257 (1975).

23. J. J. Pietron, J. F. Hicks, and R. W. Murry, J. Am. Chem. Soc., 121, 5565 (1999)

24. J. S. Abraham, F. Kitamura, K. Tokuda, and T. Ohsaka, Langmuir, 16, 876 (2000).

25. E. Shouji and D. A. Buttry, J. Phys. Chem., 103, 2239 (1999). 